\title{
CALCULATION OF THE VENOUS-ARTERIAL SHUNT IN CONGENITAL HEART DISEASE
}

\author{
BY MYRON PRINZMETAL \\ (From the University of Southern California Medical School, the Los Angeles County and \\ Cedars of Lebanon Hospitals, Los Angeles) ${ }^{1}$
}

(Received for publication July 7, 1941)

It is generally agreed that the chronic cyanosis of congenital heart disease is due essentially to a venous-arterial shunt which permits venous or unaerated blood to mix with arterial or oxygenated blood. The amount of shunt is the chief factor which determines the degree of cyanosis and the severity of the condition in a given instance. Determination of the amount of the shunt in terms of percentage of the total blood flow is, therefore, of great prognostic importance. Unfortunately, the methods for such determinations hitherto employed require data difficult to obtain and involve tedious gas and blood analyses. The values which have been recorded have been viewed with skepticism by the investigators themselves, as noted by Abbott (1). Even were the results trustworthy, these methods are unsuitable for clinical use because of their complexity and because of the protracted and painful procedures they impose upon the patients. The method proposed in this communication is one of great simplicity; it involves but a single venipuncture, and requires but twenty minutes for its completion. The procedure determines whether or not a venous-arterial shunt is present, indicates the approximate magnitude of the shunt, and provides a method for determining the true pulmonary circulation time.

\section{METHOD}

First procedure. A needle with a large bore (14 to 16 gauge) is inserted into the antecubital vein. One-half cubic centimeter of a 50 per cent solution of ether is injected, and the exact interval between the time of injection and the moment when the patient feels a prickly, burning sensation in the face is recorded. All injections are made as rapidly as possible at the beginning of inspiration. In the absence of a venous-arterial shunt this facial sensation is not experienced because all the ether is eliminated by the lungs. The occurrence of this sensation, on the other hand, testifies

1 Endowed by grants from the Beaumont Trust Fund and Henry Dazian Foundation for Medical Research. to the entry of ether into the systemic circulation by way of the shunt (2). This ether circulation time thus measures the time that it takes for the blood to travel from the arm to the right side of the heart and thence by way of the shunt to the capillaries of the face.

Second procedure. Beginning with $0.1 \mathrm{cc}$. of a 50 per cent solution of saccharine, successively larger injections are given until the smallest amount which the patient can taste is determined. If $\mathbf{5 0}$ per cent or more of the circulating blood enters the shunt, the saccharine threshold time will be equal approximately to the "ether-shunt" time because both test substances have reached the head via the short circuit. In such a case, the prognosis is grave and a precise figure is not necessary, so the test is completed at this point.

If the saccharine threshold time is considerably longer than the "ether-shunt" time, it can be concluded that more than half the blood goes through the regular channel and the approximate percentage can be calculated in the following manner.

Third procedure. Successively larger amounts of saccharine are injected. The times will remain fixed at the level of the threshold time and will exceed the "ethershunt" time by the interval required for the blood to traverse the lungs. When the injection is large enough to permit a detectable quantity of saccharine to reach the tongue by way of the shunt, the circulation time will suddenly become conspicuously shorter than in the previous estimations and will be found equal to the "ethershunt" time.

In order to understand the method of arriving at the principle of calculation of the magnitude of the shunt, it is necessary to add a few explanatory remarks. When the smallest amount of saccharine that can be tasted is determined for a patient with a venous-arterial shunt of less than 50 per cent, a certain amount of the saccharine enters the shunt and reaches the tongue, but the concentration is not sufficient to cause the material to be tasted. The true value for the threshold of taste in this instance, therefore, is not the total amount of saccharine injected, but that amount less the quantity which reaches the tongue by the short route, i.e., by way of the shunt. Except in the presence of complications, such as heart failure or polycythemia, the circulation time thus 
determined should be within normal limits, inasmuch as that part of the saccharine which is ultimately tasted reaches the tongue in the usual manner, i.e., after traversing the pulmonary circulation.

As previously stated, the saccharine circulation time is found to remain constant when increasing amounts are injected, until a point is reached when the circulation time is suddenly found to be conspicuously shorter. When this occurs, it signifies that a sufficient amount of saccharine has reached the tongue without traversing the pulmonary circulation and that the true threshold value for saccharine is now represented by the amount of this substance which reaches the tongue directly by way of the shunt.

With these facts in mind, and the necessary determinations having been made, the amount of shunt in terms of percentage of total blood flow can be calculated with the aid of the following simple calculation:

If $A$ is the smallest amount of saccharine which can be tasted in the longer circulation time period, and $C$ is the smallest amount of saccharine that can be tasted in the shorter time period, then $\frac{A}{A+C}$ would equal the amount of shunt in terms of percentage of the total blood flow, which may be called $k$. It is not necessary to determine the actual threshold value of saccharine taste sensation but only to note that it would be equal to either $A-k A$ or to $k C$, which therefore equal each other. If $A-k A=K C$, then $A=k C$ $+k A$ or $A=k(C+A)$ or $k=\frac{A}{A+C}$.

This method also enables the observer to determine the true pulmonary circulation time, i.e., the time required for the blood to travel from the right side of the heart to the left side of the heart by way of the pulmonary circulation. Inasmuch as the longer (saccharine threshold) circulation time measures the time that it takes for the blood to travel from the arm to the tongue after traversing the lungs, and the shorter saccharine circulation time measures the time that it takes for the blood to travel from the arm to the tongue without traversing the lungs, the difference between these two circulation times measures the time that it takes for the blood to traverse the pulmonary circulation. In the past it has been possible to determine the true pulmonary circulation time only by the complex radon seed method of Blumgart and Weiss (6). The latter, however, cannot be used in the presence of a venous-arterial shunt. On the other hand, the method described in this paper is not suitable for cases without venous-arterial shunt.

\section{RESULTS}

The degree of shunt in cyanotic patients with congenital heart disease was determined in four instances (Table I). The shunt was less than 50 per cent in each instance, necessitating the use of the third procedure. The percentage of shunt in each case was $11.8,21,13$, and 21 , respectively. The true pulmonary circulation times were $18,10,18$, and 14 seconds, respectively. Since the total circulation times averaged 27.5 seconds, the true pulmonary circulation time was approximately 65 per cent of the total circulation time.

One patient (Case II) did not taste saccharine when administered intravenously and a 50 per cent solution of calcium levulinate was used, the cutaneous burning sensation being utilized as the end point. One subject had Hodgkin's disease and died of this illness six weeks after the test was performed. At autopsy, in addition to the Hodgkin's disease, a patent intraventricular septal defect was found, the right ventricle was hypertrophied, the pulmonary artery was dilated to twice the size of the aorta, and marked pulmonary arteriosclerosis was present. Apparently, the greatly increased pressure in the right ventricle resulting from the pulmonary arteriosclerosis caused a venous-arterial shunt instead of the usual arterial-venous shunt through the septal defect. It was considered hazardous to make antemortem diagnoses in the other cases, but such precise information is not necessary for this study.

An example of the method follows (Case I):

\section{First procedure}

0.3 cc. ether-prickly sensation of face, seventeen seconds.

This demonstrates that a venous-arterial shunt is present. Seventeen seconds is the time required for the ether to travel from the arm through the shunt, avoiding the lungs, to the blood vessels of the face. 
TABLE I

\begin{tabular}{|c|c|c|c|c|c|c|c|c|c|c|c|c|}
\hline Caso & Age & Sex & $\begin{array}{l}\text { Cya- } \\
\text { nosis }\end{array}$ & $\begin{array}{c}\text { Red blood } \\
\text { count }\end{array}$ & $\begin{array}{l}\text { Hemo- } \\
\text { globin }\end{array}$ & $\begin{array}{l}\text { Ether } \\
\text { shunt } \\
\text { time }\end{array}$ & $\begin{array}{c}\text { Longer } \\
\text { oiroulation } \\
\text { time } \\
\text { (includes } \\
\text { pulmonary } \\
\text { ciroulation) }\end{array}$ & $\begin{array}{l}\text { Smallest amount } \\
\text { of } 50 \text { per oent } \\
\text { saocharine for longer } \\
\text { oireulation } \\
\text { time period }\end{array}$ & $\begin{array}{l}\text { Shorter oirculation time as } \\
\text { determined by } 50 \text { per oent } \\
\text { sacoharine through shunt } \\
\text { including pulmonary } \\
\text { circulation }\end{array}$ & $\begin{array}{l}\text { Smallest } \\
\text { amount of } \\
\text { gacoharine } \\
\text { for shorter } \\
\text { circulation time }\end{array}$ & $\begin{array}{l}\text { True } \\
\text { pulmo- } \\
\text { nary } \\
\text { oirou- } \\
\text { lation } \\
\text { time }\end{array}$ & $\begin{array}{l}\text { Per- } \\
\text { cent- } \\
\text { sge } \\
\text { of } \\
\text { shunt }\end{array}$ \\
\hline I & 27 & M & ++ & $8,720,000$ & $\begin{array}{c}\text { per cent } \\
116\end{array}$ & $\begin{array}{c}\text { seconds } \\
17\end{array}$ & $\begin{array}{c}\text { seconds } \\
32\end{array}$ & $\begin{array}{l}c . \\
0.4\end{array}$ & $\begin{array}{c}\text { eeconds } \\
14\end{array}$ & $\boldsymbol{\infty}$ & $\begin{array}{c}\text { eeconds } \\
18\end{array}$ & $\begin{array}{l}\text { per } \\
\text { cent } \\
11.8\end{array}$ \\
\hline II & 17 & $\mathbf{M}$ & ++ & $5,640,000$ & 97 & 16 & 15 & $\begin{array}{l}1 \\
50 \text { per cent solution of } \\
\text { calcium levulinate }\end{array}$ & 5 & $\begin{array}{l}3.75 \\
50 \text { per cent solution of } \\
\text { calcium levulinate }\end{array}$ & 10 & 21 \\
\hline III & 20 & $\mathbf{M}$ & ++ & & & 11 & 32 & 1.0 & 14 & 7 & 18 & 13 \\
\hline IV & 23 & $\mathbf{F}$ & ++ & $5,780,000$ & 75 & 14 & 31 & 0.8 & 17 & 3 & 14 & 21 \\
\hline
\end{tabular}

\section{Second procedure}

0.1 cc. 50 per cent saccharine.... not tasted. 0.2 cc. 50 per cent saccharine.... not tasted. 0.3 cc. 50 per cent saccharine.... not tasted. 0.4 cc. 50 per cent saccharine.... sweet taste, 30 seconds. 0.4 cc. 50 per cent saccharine.... .sweet taste, 34 seconds. 0.3 cc. 50 per cent saccharine.... not tasted.

0.4 cc. 50 per cent saccharine.... sweet taste, 35 seconds.

The patient could not taste $0.3 \mathrm{cc}$. of a 50 per cent solution of saccharine, but always tasted $0.4 \mathrm{cc}$; $0.4 \mathrm{cc}$. is therefore the threshold volume. Since the saccharine threshold time (thirty to thirty-five seconds) is so much longer than the "ether-shunt" time (seventeen seconds), it can immediately be concluded that most of the blood goes through the lungs, by way of the normal circulation, and less than one-half of the cardiac output goes through the shunt. The approximate per cent can now be determined by injecting increasingly larger amounts of saccharine until the shorter circulation time is attained.

\section{Third procedure}

2.0 cc. saccharine..............sweet taste, 32 seconds. 2.5 cc. saccharine.............. sweet taste, 31 seconds. 2.75 cc. saccharine.............sweet taste, 32 seconds. 3.00 cc. saccharine............. sweet taste, 14 seconds.

From the determinations, it is apparent that in $2.75 \mathrm{cc}$. of 50 per cent saccharine, the volume going through the shunt was not sufficient to cause the taste sensation since the circulation time was 32 seconds. In 3.0 cc., however, enough of the solution went through the shunt to cause the sweet taste to occur at a time approximately equal to the "ether-shunt" time, and much faster than the previous injections. Since the taste threshold of saccharine is $0.4 \mathrm{cc}$., the approximate volume of the shunt can now be determined by means of the formula:

$$
K=\frac{A}{A+C}
$$

Volume of shunt:

$$
\frac{0.4}{0.4+3.0}=11.8 \text { per cent. }
$$

The true pulmonary circulation time can be determined by subtracting the shorter circulation time (fourteen sec- onds) from the total circulation time (thirty-two seconds), which excludes the pulmonary circulation. In this case, it is approximately eighteen seconds.

\section{DISCUSSION}

The shunt in all four patients is quite small and this undoubtedly explains the comparative well-being of these subjects in spite of the malformation of their hearts. The method is probably not suitable for children unless they are able to cooperate. In the very few cases in which the shunt was determined previous to this study, larger figures were obtained $(3,4,5)$.

The prolongation of the circulation time in some of our patients may be due to the polycythemia. The effect of this factor on the circulation time has been previously noted (7). Persistent cyanosis in those who have congenital heart disease is a result of (1) a septal defect in the presence of pulmonary stenosis, (2) a complete absence of the cardiac septa, or (3) the transposition of the great trunks. In addition, there are other rarer conditions which are occasionally responsible. The method described in this communication for determining the magnitude of the venous-arterial shunt does not indicate which of the above conditions exists in a given case. In the absence of characteristic findings in the cases herein reported, it was considered hazardous to make a precise anatomical diagnosis.

This method cannot give exact figures if the shunt is greater than 50 per cent, but the knowledge that a shunt of this degree exists is of sufficient value to make a precise figure unnecessary. The streaming of the saccharine through the lungs should be greater than that going directly through 
the shunt. The solution going through the lungs becomes more diluted than that going through the shunt. This introduces an error, the magnitude of which is unknown. This factor affects only the third, not the first two procedures. It is therefore apparent that, if the shunt is less than 50 per cent, the accuracy of the figure obtained can be considered only approximate, but this approximate value should be extremely useful from a prognostic point of view.

\section{CONCLUSIONS}

A simple method has been described for determining the presence of a venous-arterial shunt in congenital heart disease, the magnitude of the shunt, and the true pulmonary circulation time in the presence of shunt.

The author desires to thank Doctors E. Bogan, L. T. Bullock, B. Sachs, and W. P. Thompson for aid in this study.

\section{BIBLIOGRAPHY}

1. Abbott, M. E., The diagnosis of congenital cardiac disease. Blumer's Bedside Diagnosis, Vol. II. Saunders, Philadelphia, 1928, p. 353.

2. Benenson, W., and Hitzig, W. M., Diagnosis of venous arterial shunt by ether circulation time method. Proc. Soc. Exper. Biol. and Med., 1938, 38, 256.

3. Krogh, A., and Lindhard, J., Measurement of the blood flow through the lungs of man. Skandinav. Arch. für Physiol., 1912, 27, 100.

4. Raab, W., and others, Untersuchungen über einen Fall Von kongenitalem Herzvitium. Wien, Arch. f. inn. Med., 1924, 7, 367.

5. Abbott, M. E., and Dawson, W. T., The clinical classification of congenital cardiac disease, with remarks upon its pathological anatomy, diagnosis and treatment. Internat. Clinics, 1924, 4, 156.

6. Blumgart, H. L., and Weiss, S., Studies on the velocity of blood flow. VII. The pulmonary circulation time in normal resting individuals. J. Clin. Invest., 1927, 4, 399.

7. Blumgart, H. L., The velocity of blood flow in health and disease. The velocity of blood flow in man and its relation to other measurements of circulation. Medicine, 1931, 10, 1. 